\title{
LO IMAGINARIO DEL CUERPO EN LA TECNOCIENCIA
}

David Le Breton $^{1}$

Universidad de Strasbourg

\section{EL CUERPO ALTER EGO}

En la representación científica contemporánea y en las realizaciones actuales de la biomedicina, la unidad fenomenológica del hombre estará, de ahora en adelante, fragmentada. Un dualismo de una nueva especie está cobrando importancia en sus diversas facetas, haciendo del cuerpo un doble del hombre, un alter ego que se beneficia de la atención o del rencor del actor según las figuras que éste diseñe. Para la tecnociencia, la especie humana parece teñirse de una corporeidad que recuerda demasiado a la humildad de su condición. Reconstruir el cuerpo humano parece el desafío al cual se unen estos nuevos ingenieros de lo biológico. La representación tecnocientífica se encamina por la vía de la desconfianza; ella instruye el proceso al cuerpo por medio de la constatación de la precariedad de la carne, de su falta de resistencia, de su imperfección en la aprehensión sensorial del mundo, del envejecimiento progresivo de las funciones y de los órganos, la falta de fiabilidad de sus capacidades y la muerte suspendida, albergada en el seno del dispositivo orgánico de la

Doctor en Sociología, Catedrático de la Universidad de Strasbourg; autor, entre otros, de Anthropologie du corps et modernité (PUF, 1990); Passions du risque (Métailié, 1991); Lo sociologie du corps (PUF, 1992); Des visages. Essai d'anthropologie (Métailié, 1993); La chair à vif. Usages médicaux et mondains du corps humain (Métailié, 1993). Anthropologie de la donleur (1995).

\section{Reis


vida. Parece hacer del cuerpo un miembro supernumerario del hombre e incentivar su liberación. Esta representación de la denigración reprocha al cuerpo su falta de dominio sobre el mundo, la disparidad bastante nítida que existe entre una voluntad de dominio, que es incesantemente desmentida por la condición eminentemente precaria del hombre. Esta representación se vuelve con resentimiento hacia un cuerpo marcado por el pecado original de no ser más que un puro objeto de la creación tecnocientífica.

Esta representación no es necesariamente explícita, aunque a veces lo sea; aparece, sin embargo, como el móvil más o menos consciente que anima numerosas investigaciones técnicas y científicas, numerosas prácticas cuya voluntad consiste en paliar las incertidumbres de lo orgánico, añadiéndole procedimientos técnicos, métodos de gestión que supuestamente hacen, gracias a su concurso, un objeto maleable y sólido. El cuerpo no es en absoluto un lugar de dominio para el médico o el ingeniero que, a menudo, se ponen de acuerdo para tratarlo como un borrador y llevarlo a la perfección última que no busca más que la corrección de la ciencia. La visión moderna y laica de la ensomatosis (la caída en el cuerpo en antiguas tradiciones agnósticas), la carne del hombre que encarna su parte maldita según innumerables sectores de la tecnociencia, se adhieren, felizmente, para remodelar, rehacer, «inmaterializar», transformar en mecanismos controlables, para de alguna manera liberar al hombre del embarazoso arraigo carnal donde maduran la fragilidad y la muerte ${ }^{2}$. Este cuerpo denigrado no encuentra resto de valor más que en su asimilación a la máquina.

Frente al problema de su constitución carnal, el cuerpo se disocia del hombre al que encarna y se considera como uno en sí mismo. Así, la biotecnología o la medicina moderna privilegian al mecanismo corporal, la disposición en engranajes de un organismo percibido como una colección de órganos y de funciones potencialmente sustituibles. El sujeto, en tanto que tal, aparece como residual, sólo se lo trata indirectamente por medio de una acción que tiende a la organicidad.

La versión moderna del dualismo opone al hombre a su propio cuerpo ya no como sucedía antiguamente, donde se enfrentaba el alma o el espiritu al cuerpo. Fragmentación de la identidad personal que responde como un eco a la fragmentación del actor en la modernidad e ilustra la agudeza de la ruptura. La parte maldita en vías de rectificación por medio de las tecnociencias o en vías de salvación, sustituyéndose al alma en una sociedad laica, la misma distinción que pone al hombre en posición de exterioridad, de testigo de alguna manera, frente a su propio cuerpo.

2 En las prácticas de ocio o la puesta en escena de sí mismo en la vida cotidiana el cuerpo puede ser objeto de la atención sostenida del actor, de una preocupación por la apariencia, etc. Sin embargo, incluso aquí, el cuerpo está en posición de hacer valer, casi representante de sí mismo, es también socio privilegiado del diálogo, de la investigación, y del amor a sí mismo. Está igualmente en posición de alter ego. Sobre este punto y aquellos mencionados anteriormente de David Le Breton, Anthropologie du corps et modernité, PUF, 1990. 


\section{LA INVENCION DEL CUERPO: LOS ANATOMISTAS}

El momento inaugural de la ruptura concreta entre el hombre y su cuerpo surge con la tentativa iconoclasta de los primeros anatomistas, que abren realmente los cuerpos humanos. Aislado del hombre, el cuerpo se transforma en objeto, en una curiosidad irreversible. La interrogación sobre el estatuto antropológico del cadáver con vistas a utilizar rápidamente sus componentes es una antigua cuestión que aparece como telón de fondo en toda la historia de la medicina. Una lucha feroz que durante mucho tiempo ha opuesto a los anatomistas y a las poblaciones horrorizadas por las disecciones y desoladas por la frecuente violación de las sepulturas ${ }^{3}$.

Desde Vesalio y los primeros anatomistas, la representación médica del cuerpo deja de ser solidaria con la imagen integrada del hombre. La publicación en 1543 de De humani corporis fabrica supone un momento simbólico de esta mutación epistemológica que conduce, a través de diferentes etapas, a la medicina contemporánea. Los anatomistas, anteriores a Descartes y la filosofía mecanicista, fundaron un dualismo que está en el seno no solamente de la medicina, sino también de la modernidad, que distingue al hombre por una parte y a su cuerpo por otra. Recordemos la imagen de Marguerite Yourcenar en la Opus nigrum cuando Zenón, médico próximo a Vesalio, se inclina con su compañero, también médico, sobre el cadáver de un joven, el hijo del anterior: «En la habitación impregnada de vinagre donde disecamos a este muerto, que ya no era más el hijo ni el amigo, sino solamente un bonito ejemplar de la máquina humana» ${ }^{4}$. Frase programática que nos sumerge en el seno de la modernidad y nos aclara acerca de la abundancia de problemas éticos a los cuales se enfrentan nuestras sociedades contemporáneas; la medicina moderna no se ocupa del hombre, sino del cuerpo enfermo; ella trata a "la máquina humana», pero no al hijo o al amigo, es decir, al hombre en su singularidad. Los problemas que se presentaban aún con una discreción relativa hace algunos años toman una amplitud considerable con la acentuación y refinamiento de los medios técnicos, la especialización de los cuidados, la preocupación por la salud y, sobre todo, la creciente información de los usuarios.

El cuerpo humano, desde entonces, va a ser sujeto de innumerables investigaciones de la puesta entre paréntesis, del hombre al que encarnó. La formulación del cogito por Descartes prolonga históricamente la disociación implícita del hombre y de su cuerpo despojado de valor propio. No retomaremos aquí esos análisis. Sin embargo, recordemos que se hace cada día más cierto el principio que Descartes formula con claridad, un tema clave de la filosofía mecanicista del siglo XVII: el modelo del cuerpo consiste en la máquina, el cuerpo humano es un mecanismo discernible de otros por la única singularidad de sus

3 David Le Breton, La chair à vif. Usages médicaux et mondains du corps humain, París, Métailié, 1993.

${ }^{4}$ Marguerite Yourcenar, L'Oeuvre au noir, Gallimard, p. 118. Versión española Opus nigrum, Alfagura, Buenos Aires, 1994. 
engranajes. Esto no es más que un capítulo particular de la mecánica general del mundo. Proposición llamada a un futuro próspero en la representación técnica occidental. Ilustrando, además, el sentimiento de la potencia que ha invadido las filosofías mecanicistas, ebrias por la ruptura epistemológica que actúa sobre ellas, el autómata nacido de manos del artesano se presenta como una figura de la creación. El hombre aparece así menos como criatura que como rival del Dios mecánico. El cuerpo es una máquina a imagen del reloj, y las máquinas fabricadas por Dios, artesano supremo, siendo las mejores dispuestas, no dejan de ser más que máquinas. La única diferencia entre el reloj, hecho por la mano del hombre y el cuerpo humano, nacido del ingenio divino, es la alta complejidad de este último mecanismo. Pero, en el fondo, a la actividad del hombre no le afecta esta comparación. Descartes solamente concede a Dios el justo privilegio de ser un artesano más hábil que los otros.

\section{SABER SOBRE EL ORGANISMO, SABER SOBRE EL HOMBRE}

El saber biomédico es un saber sobre el organismo, que hace del hombre un doble sin valor. La base epistemológica de la medicina descansa sobre un estudio riguroso del cuerpo, pero separándolo del hombre, a menudo percibido como un intruso con el que el médico debe componer (el ritual de la visita médica al hospital es una ilustración penosa y caricaturesca). Ello hace del hombre el propietario, más o menos feliz, de un cuerpo que persigue sus biológicas propias. La enfermedad no es percibida ni tratada como el efecto de la aventura personal de un hombre inscrito en una sociedad y en un tiempo dados, sino como el defecto anónimo de una función o de un órgano ${ }^{5}$. El mismo hombre es alcanzado indirectamente, sin ser explícitamente cuestionado, excepto en la ficción de la media epidemiológica a través de sus hábitos alimentarios, su ritmo de vida, su consumo de tabaco y alcohol y otros datos. La medicina descuida estructuralmente ${ }^{6}$ la dimensión humana, su progreso personal, su contexto familiar o relacional, su angustia, y considera esencialmente el «mecanismo corporal» que aparece en el examen del médico o en las técnicas de la imagen. En este sentido, la reflexión ética es ajena a la medicina, es una clase de suplemento del alma abandonada a la discreción del practicante. La ética trata, en efecto, del hombre, en tanto que éste está inserto en el seno de

Arthur Kleinman plantea la necesidad para el médico, en cuanto a la pertinencia del diagnóstico, y la calidad de los cuidados, la toma en cuenta de la percepción por el enfermo de su enfermedad y del significado personal que ésta posee para él. Cf. Arthur Kleinman, The illness narratives. Suffering and heling and the human conditions, New York, Basic Books, 1988.

${ }^{6}$ El médico, como tal, en el coloquio singular no lo puede hacer. La práctica de la medicina general está aquí, por otra parte, en posición favorable. El médico clínico es, a menudo, un médico que en su terapia toma al hombre en su medida humana. Conoce el arraigo social y cultural de su paciente. Le puede considerar también en la dinámica relacional de su grupo familiar. 
un grupo social y cultural y comparte con sus pares un conjunto de referencias, de sentidos y de valores. Pero la medicina trata esencialmente del organismo y sus parámetros. Históricamente, ha apostado por el cuerpo (por una cierta representación de aquél), descansando en una antropología a mínima. La serie de especializaciones en torno a ciertas funciones, ciertos órganos, ciertas patologías, la estructura hospitalaria que dibuja en el espacio un cuerpo humano dividido en trozos, el uso de técnicas de imagen cada vez más elaboradas en el afinamiento del diagnóstico, el recurso a los medios terapéuticos cada vez más tecnificados son, entre otros, los modos de acercamiento de la medicina al cuerpo humano enfermo, pero que ponen al enfermo entre paréntesis, como si fuera el suplemento despreciable y algunas veces reacio a una enfermedad sólo digna de interés y cuidado. El cuerpo humano aparece como objeto de un extremo desmenuzamiento. El hombre está concebido in abstracto como el fantasma reinante en un archipiélago de órganos y funciones metodológicamente aislados los unos de los otros. Además, a través de la herencia de la filosofía mecanicista, el cuerpo se asimila a una máquina sofisticada y la medicina puede entenderse, por un hombre como Lucien Israel, como «la ciencia de las averías» ${ }^{7}$. El enfermo se convierte en una especie de epifenómeno de un acontecimiento fisiológico (la enfermedad) que no le afecta más que de forma indirecta. El lenguaje de ciertos enfermos es revelador en este sentido («es el cuerpo que empieza a desgastarse», "tengo el corazón que hace de las suyas», "es mi tasa de colesterol», "la mecánica ya no es lo que era», etc.). O, algunas veces, la rutina de ciertos servicios hospitalarios («el pulmón de la 12», "la escara de la 15»). Estas son las expresiones corrientes de una versión instrumental del cuerpo («reparar el cuerpo») registrando bien el dualismo que disocia al hombre de su carne; dualismo a partir del cual la medicina ha establecido sus procedimientos de investigaciones y curas. La medicina despersonaliza la enfermedad; para actuar mejor sobre ella (y a menudo con eficacia) ${ }^{8}$ la hace anónima, indiferente al hombre al que afecta. Esta concepción lleva al enfermo a entregarse de forma pasiva en manos del médico y a esperar a que el tratamiento recibido haga su efecto. Su patología es diferente a él; su esfuerzo por sanar y su colaboración activa no se consideran esenciales; se le pide, justamente, ser paciente, es decir, pasivo y dócil, confiar en el mecánico que le trata y no ser un hombre activo en la comprensión de su patología y el proceso de la curación. Tal es el obstáculo de una medicina que no es la del sujeto, que recurre a un saber del cuerpo donde el hombre concreto está ausente.

«La medicina es una ciencia de averías ... no hay nadie que pida que la máquina se ponga en movimiento para siempre ... basta con que funcione de manera aceptable por un tiempo.» L. IsRael, La décision médicale, Calmann-Levy, 1980, p. 54.

${ }^{8} \mathrm{O}$ «deshumaniza», como escribía René Leriche, para quien este enfoque no fue más que la primera parte de un análisis que introducía luego el concepto de enfermo. 


\section{EL CUERPO COMO «BORRADOR»}

En las sociedades occidentales desde el Renacimiento, la historia del cuerpo se escribe con un creciente dominio, en el interior de un marco tecnocientífico que la ha distinguido del hombre, desacralizado y reducido a una versión novedosa del mecanismo. $\mathrm{Y}$, en efecto, cuando la dimensión simbólica se retira del cuerpo, no queda de él más que un conjunto de mecanismos, una disposición técnica de funciones sustituibles. Lo que entonces estructura la existencia del cuerpo no es más la irreductibilidad del sentido y del valor, el hecho que es la carne del hombre, sino la permutación de los elementos y las funciones que aseguran el orden.

Extraído del hombre que lo encarna, como si fuera un objeto vaciado de su carácter simbólico, el cuerpo lo está también de su dimensión axiológica. Está desprovisto de su halo imaginario, de su dimensión sacra. Es el envoltorio accesorio de una presencia, una arquitectura de materiales biológicos cuyo conjunto de piezas es signo de una equivalencia generalizada con la de otros cuerpos. Sin embargo, una sospecha pesa sobre él, que revela ya la fecundidad de la cirugía correctiva que multiplica desde el siglo XVII las prótesis para enderezar el cuerpo, para perfeccionarlo\%. La tecnociencia contemporánea se inscribe en la línea recta de una búsqueda que, desde entonces, no ha sido desmentida: cómo hacer de este cuerpo-borrador un objeto fiable, digno de procedimientos rigurosos del pensamiento científico. En efecto, este último es testigo de una relación extrañamente ambivalente con el cuerpo: a la vez él es su antimodelo, le evita, intentando desembarazarse, pero al mismo tiempo buscando sin cesar duplicarle con los medios propios y de forma inhábil. El ejemplo más contundente es probablemente el de la fecundación asistida médicamente, presentada de forma unánime como una formidable victoria de la ciencia. Sentimiento apenas compartido por la mayoría de las parejas que se han visto engañadas, por una u otra razón, a causa de una reputación usurpada ${ }^{10}$.

Quizás toda la historia de las técnicas y las ciencias desde el siglo XVII no sea más que la historia de las correcciones llevadas a cabo sobre las insuficiencias (a los ojos de los técnicos y de los científicos) del cuerpo, innumerables bifurcaciones para escapar de su precariedad, de sus límites, dominar esta parte inasequible de la carne. Tentación demiúrgica de corregirle, de modificarle a falta de hacer de él una máquina realmente impecable. En el marco del pensamiento laico subyace un fantasma implícito, informulable: abolir al cuerpo, eclipsarle pura y simplemente sustituyéndolo por una máquina de mayor perfección.

La lucha contra el cuerpo revela cada vez más la representación que la sustenta: el miedo a la muerte. Corregir el cuerpo, haciendo de él un mecanismo,

9 Cf. Georges Vigarello, Panoplies redresseuses, jalons por une histoire, Traverses, 14-15, 1979, pp. 14-15.

${ }_{10}$ Por ejemplo, Jacques Testard, Le magasin des enfants, François Bourin, 1990. 
asociarle a la idea de la máquina o emparejarle con ella, es escapar a lo transitorio, borrar "La insoportable levedad del ser»(Kundera). El cuerpo, lugar de la muerte en el hombre; ¿no es acaso lo que olvida Descartes, como un lapsus, cuando en sus Meditaciones la imagen de un cadáver se impone a su razonamiento para designar su condición corporal?: "yo me consideraría, primero, como poseedor de una cara, de manos, de brazos, y toda esa máquina compuesta de hueso y carne, tal como aparece en un cadáver, a la cual designaba bajo el nombre de cuerpo ${ }^{11}$. Imagen aún más inquietante y menos necesaria.

\section{EL HOMBRE COMO «RESIDUO»}

Ciertamente, la asimilación del cuerpo a un mecanismo choca contra el residuo del que está obligado a ignorar so pena de invalidarse: el hombre. El conjunto de problemas éticos que debe afrontar hoy en día la medicina está ligado al dualismo que la estructura, tratando la enfermedad antes que al enfermo y a los aparatos que se implantan a los usuarios con un grado variable de adhesión. El relevo técnico de lo orgánico, es decir, el acoplamiento del cuerpo y de la máquina, realizado concretamente, es una línea frontal de oposición de los usuarios de la medicina: la soledad de los moribundos, y la dificultad de acompañarles, el ensañamiento terapéutico, la eutanasia, los enfermos en estado de coma vegetativo crónico mantenidos con reanimación, etc. La medicina en su versión más técnica descubre súbitamente con estupor al hombre oculto bajo el cuerpo. El inhibido irrumpe en la escena médica. La última protesta de este residuo: el hombre, cuando no se ocupa más que de su organismo, como de una máquina, para mantenerlo en un estado de funcionamiento mínimo.

\section{LA «MAQUINA» DEL CUERPO}

Un diccionario moderno de ideas y prejuicios, refiriéndose al cuerpo, dirá: «una maravillosa máquina». Pero la formulación es ambigua, es testimonio de una ambivalencia. En tanto que la réplica a la falta de los orígenes que un buen número de procedimientos se esfuerza por corregir, la asimilación mecánica del cuerpo humano que deja a un lado al hombre en sí, traduce en el contexto de la modernidad, la única dignidad que es posible conferir al cuerpo. No se compara la máquina al cuerpo, sino que se compara el cuerpo a la máquina. La comparación no puede ir más que en este sentido; paradójicamente, el mecanismo da al cuerpo sus dudosas cartas de nobleza, signo indiscutible de la procedencia de los valores para la modernidad. Si no está subordinado a la máquina, el cuerpo no es nada. La admiración de biólogos o cirujanos ante el cuerpo

${ }^{11}$ Descartes, Meditations philosophiques, París, PUF, 1970, p. 39. 
humano en cuyos arcanos intentan penetrar, o aquella más cándida del profano, se traduce por el mismo grito: "Qué máquina tan maravillosa». Son innumerables, a este respecto, los títulos de obras o de artículos que recurren a la metáfora mecanicista. Hasta el enfermo de los servicios hospitalarios se deja engañar. El médico "mecánico», el hospital «estación de servicio» donde se tratan en cadena las máquinas orgánicas defectuosas, son imágenes que resultan ser triviales para un discurso crítico que, frecuentemente, ensalza a la inversa las medicinas paralelas de las cuales uno de los méritos es rechazar la dislocación del sujeto y tratar a este último de un modo holístico.

De la admiración ante la "máquina maravillosa», el discurso científico o técnico pasa rápidamente a la postura en pro de la fragilidad que la caracteriza. A máquina, máquina y media. Para un cierto discurso médico el cuerpo no merece de forma rotunda una apelación tal. El envejece, su precariedad le expone a lesiones irreversibles. Ni goza de la permanencia de la máquina, ni dispone de las condiciones que permitan controlar el conjunto de procesos que se ponen en juego. El dolor y la muerte son el precio a pagar por la perfección relativa del cuerpo, lo simbólico de su vasallaje a la historia personal de un actor sumergido en una sociedad, el placer y el dolor son los atributos de la carne, implican el riesgo de la muerte y de lo simbólico social. La máquina es igual, quieta, no siente nada porque escapa de la muerte y de lo simbólico. Para la tecnociencia, la carne del hombre está dispuesta a la confusión, como si hubiera que perder una, si cabe, realidad gloriosa. La metáfora mecánica aplicada al cuerpo resuena como una reparación para conferirle a éste una dignidad que no sabría tener siquiera siendo simplemente un organismo. Nostalgia de una condición humana que no estaría más en deuda con el cuerpo carnal, lugar de la caída, de la precariedad, pero que accedería por último al cuerpo glorioso creado por la tecnociencia. El cuerpo, vestigio multimilenario del origen no técnico del hombre.

Cuerpo supernumerario al que el hombre debe su precariedad y al que se preocupa de cerrar herméticamente al envejecimiento o a la muerte, al sufrimiento o la enfermedad. "La mutación más espectacular que conmueve a nuestro universo es sin duda la reificación del hombre — escribe Philip K. Dick-, pero esta mutación se acompaña al mismo tiempo de una humanización recíproca de lo inanimado por la máquina. No podemos, en lo sucesivo, oponer más las categorías puras de lo vivo y de lo inanimado, y esto va a convertirse en nuestro paradigma» ${ }^{12}$. La sociología imaginante de Philip K. Dick suscita las cuestiones más inquietantes del mundo moderno.

Marx Rokheimer veía sobre los rasgos de Hamlet el primer individuo moderno, y en los propósitos de éste la expresión naciente de la cuestión ontológica. Las primicias de la disolución de las fronteras entre lo humano y lo mecánico llevan hoy en día a una interrogación ontológica de un nuevo género. En la era de la modernidad triunfante, Philip K. Dick nos sugiere irónica-

12 Philip Dick, L'homme l'andrö̈de et la machine, in Les défenseurs, 18-10, 1989, p. 8. 
mente la cuestión que formula con la más profunda de las dudas que el hombre occidental alimenta de cara a su propia identidad: ¿sueñan los androides con ovejas eléctricas? ${ }^{13}$.

\section{EL CUERPO, MIEMBRO SUPERNUMERARIO}

El hombre difiere de la cosa, y sobre todo de la máquina, por el hecho de nombrarla; la integra en un sistema de significación y valores, aun cuando decide ver en ella un valor superior a los suyos propios. Desde entonces, hace de su creación la prueba a cargo de su indignidad. Lógica absurda, pero que recuerda que la condición humana se trama en la dimensión simbólica y que compete al hombre decretar que es poca cosa, incluso nada de nada, ante otras instancias, obras del mismo cuya superioridad se afirma. Así el cuerpo humano es puesto de plano sobre el modelo de la máquina, desprovisto de su valor de encarnación de la presencia del hombre, como un objeto entre otros. Los avances técnicos y científicos confrontan los imaginarios sociales con un cuestionamiento delicado que levanta toda una serie de preocupaciones éticas. Asistimos a la toma al pie de la letra de la metátora que hoy en día lleva a hacer del cuerpo humano un material disponible.

Cuanto más pierde el cuerpo su valor moral, más aumenta su valor técnico y mercantil. Sus componentes se transforman en una materia prima preciosa y rara, porque sumisa todavía a una cláusula de conciencia y a un debate en el campo social. El cuerpo humano se decanta por materiales, la mayor parte de ellos, que entran en el registro de la posesión, que se asimilan a los bienes casi patrimoniales del individuo. Puesto en otro plan de valor, entrando en una lógica mercantil o casi, estos materiales son objeto de comercio y tráfico por parte de ciertos países o de trasplantes (riñones, testículos, sangre, etc.), están aislados de un hombre puesto en ingravidez. El cuerpo toma el valor de objeto a precio inestimable en espera de la demanda. Las necesidades de órganos o de sustancias humanas están destinadas a cuatro usos por lo menos: la investigación médica y biológica, gran consumidora de muchos materiales humanos; la fabricación de productos farmacéuticos, los trasplantes que los progresos de la cirugía hacen cada vez más frecuentes y más diversificados y, por último, los usos tradicionales de las facultades de medicina (sobre todo las disecciones). Por otra parte, la gestión tecnológica del cuerpo abre una vía a las nuevas prácticas para las que se anuncia un futuro próspero: secuencia del genoma, procreaciones asistidas, alquileres de úteros, investigaciones en embriones congelados, intervenciones en los genes, etc.

13 Recordemos que éste es el título original americano de una novela adaptada al cine por Ridley Scott bajo el título Blade Runner. El éxito de la película ha hecho que el título de Ridley Scott se convierta en el de una novela. Es lo que hace perder el humor trágico que se disimula en esta frase en apariencia absurda pero particularmente juiciosa para quien haya leído la novela. 
La humanidad se convierte en una noción a modulación variable: una ficción algo problemática define al hombre e indica su entorno, dándole forma a una serie de órganos o funciones, llegado el caso, desmontables. El hombre se transforma en potencia en una clase de fantasma susceptible de retirarse de este o aquel de sus componentes, sustraídos de sí e incluidos en el registro inédito del objeto biológico humano. Aún es, a veces, susceptible de retirarse enteramente de una corporalidad animada cuando los médicos reclaman el poder experimentar sobre hombres en "coma crónico", o cuando llega el momento de retirarse y dejar su cuerpo al manipulador de la medicina legal o a los estudiantes en los anfiteatros. La corporalidad que da al hombre la carne de su relación al mundo vuela en pedazos y se convierte en un puzzle biológico establecido sobre el modelo de una mecánica humana donde cada elemento es sustituible por otro, llegado el caso, con mejores prestaciones. El hombre, fuente sagrada, en aquello que simboliza el mundo que le rodea, se transforma él mismo en objeto profano, cuyos elementos relevan de su patrimonio objetos susceptibles de desmembración o experimentación en la medida en que la noción de humanidad se hace facultativa en lo que concierne a muchos órganos y funciones.

$\mathrm{Al}$ asimilar la persona estrictamente a las funciones cerebrales, definición moderna del alma, de alguna forma, la medicina decide que la muerte del sujeto es el hecho de la destrucción irreversible del cerebro. Aunque, cuidadosamente relevado por las tecnologías médicas, el organismo biológico persigue hasta el infinito su periplo. La muerte es la decisión administrativa de «desconectar la máquina». El dualismo médico que descuida al hombre para preocuparse por un cuerpo enfermo con su precisión relojera se confronta con situaciones insolubles. Una definición secuencial del hombre llega a la determinación lógica de una sucesión de muertes que afectan al mismo individuo. Un ejemplo: el 29 de marzo de 1983 una joven californiana dio a luz a un niño después de una cesárea. La misma joven estaba cerebralmente muerta el 9 de enero, nueve semanas antes, y sus funciones orgánicas mantenidas artificialmente en actividad. El equipo médico lo decidió así para que continuara el desarrollo del feto. El niño vino al mundo prematuramente después de treinta y una semanas de gestación pues su maduración había cesado. A continuación los médicos «desconectaron» a la joven que, así, conoció una segunda muerte. En uno y otro caso los médicos se preocuparon de mantener con vida los organismos y no los individuos. El futuro de un niño nacido de una madre muerta no les preocupaba. La responsabilidad tiene también la ventaja moral de convertirse en secuencial. Pero la fragmentación del individuo suscita preguntas temibles: «Ahora —observa Douglas Shrader-, cuando nos preguntamos por alguien que esté en un coma irreversible: “¿Es un ser humano o un muerto?” Nada más justo que responder: "Vivo, en un cierto sentido; muerto, en otro" ${ }^{14}$. El cirujano ameri-

${ }^{14}$ Douglas Shrader, "On dying more than one death», Hastings Center Report, febrero 1986, p. 14. 
cano Norman Shomway da una definición asombrosa, eminentemente moderna en 1970: «Digo que alguien cuyo cerebro está muerto, está muerto. Es un punto universalmente aplicable, pues el cerebro es el único órgano que no puede trasplantarse.» Soberbia definición por defecto.

Si el cuerpo deja de ser la persona, si está alejado de un individuo hacia un estatus cada vez más indecible, si el dualismo no se inscribe más en la metafísica, pero decide de lo concreto de la existencia y funciona como un modelo de la acción médica, entonces todo está permitido. El cuerpo se convierte en un mecano biológico sobre el que reina en potencia un hombre que no es más que la suma de esta sutil articulación. Enunciable en sus elementos sucesivos es susceptible de todos los arreglos, de combinaciones insólitas con otros cuerpos o de experimentaciones sorprendentes. El yacente de la sala de reanimación es un cuerpo sin hombre, una medalla sin reverso. Su cerebro dormido o destruido permite destituirle de toda dignidad. El hombre se desvanece en un polvo de componentes, la muerte no altera más su aspecto ni su cuerpo, nadie sabe más dónde está, si está vivo o muerto, presente o ausente, y sus parientes ignoran si deben llorar o esperar aún. El lenguaje fracasa al rendir cuenta de una pura creación de la modernidad tecnológica que cambia completamente las antiguas definiciones del hombre, por las realizaciones lejos de hacer la unanimidad, pero que erige al médico en dueño de la hora, que dice y decide la muerte.

La muerte en detalle de las diferentes partes del cuerpo, de la que antes hablaba Bichat, se convierte con la tecnología médica moderna en muerte sucesiva del mismo individuo que deja a las familias atónitas. El cerebro o el corazón quedan destruidos, pero el individuo continúa dando apariencias de vida. Está muerto y enterrado desde hace años, pero sus riñones, su corazón, sus pulmones, su páncreas, etc., funcionan en el cuerpo de varios individuos cuyos órganos enfermos han sido reemplazados por los de este hombre que se ha convertido en fantasma con una cara diferente en la imaginación de cada uno de ellos. Sin el corazón trasplantado, el injerto estaría muerto, pero a su muerte, ¿quién se extingue? Y si el médico trasplanta una vez más el corazón del anterior trasplantado, ¿qué órgano entra en el cuerpo de aquel que lo recibe del muerto? El mismo donante inicial conoce una multitud de muertes. Los trasplantes plantean problemas insolubles al igual que las procreaciones asistidas médicamente que pueden hacer de la madre de una joven la madre de su hijo o convertirla a la vez en su madre y su hermana, mientras que para el niño su madre será su hermana y su abuela será su madre, etc.

La voluntad de hacer «útil» a toda costa al paciente al término de su vida, de no perder nada de los componentes físicos tan preciados, lleva a la formulación clara y deliberada de un proceso aún implícito y disperso: explotar de manera sistemática estos viveros de órganos o de sangre de esos cuerpos sin hombre, con el cerebro en desuso. Sustancia viva ascendida a un reino intermedio, indecible entre hombre y animal, una nueva especie de laboratorio ha nacido. El «testamento de la vida» que proponen ciertos médicos es, justamen- 
te, una tentativa de legalizar estos trámites solicitando al individuo, aún dueño de sus decisiones, toda licencia de sacar sus órganos o experimentar sobre él si se encontrara algún día en estado irreversible.

El psiquiatra americano W. Gaylin ${ }^{15}$ sugiere la creación de bancos de «neomuertos», es decir, de individuos en estado vegetativo crónico incalificables en el plan antropológico y disponibles durante años para tomar muestras de órganos, ojos, sangre, médula espinal, piel, etc. Se mantendrán con vida de modo artificial (en marcha) en una granja de un nuevo género: el bioemporium. Los estudiantes practicarán en ellos para los trasplantes de todo tipo, operaciones quirúrgicas delicadas en la cara, los ojos, el corazón, las muestras de piel, etc. Unos denunciarán lo que otros reparen hasta el infinito en el mismo organismo. Estos cuerpos estarán disponibles para los ensayos terapéuticos o farmacológicos. Los estudiantes repetirán sobre éstos los gestos médicos (oscultación, examen de retina, exploración anal o vaginal, etc.). Los cirujanos probarán las extracciones y trasplantes de órganos. Se podrán inyectar las enfermedades de sangre y probar diferentes terapias, sin perjudicar a otras categorías de población $^{16}$. Cada fragmento de su cuerpo informatizado, clasificado para la investigación de compatibilidades, los neomuertos esperarán con paciencia las extracciones sucesivas, mientras sirvan de materiales para toda clase de manipulaciones o experimentos. No hay duda que la ferviente imaginación médica será infinita para rentabilizar a estos individuos. Gaylin concluye su artículo preguntándose si tal uso del cuerpo humano no amenaza con «destruir estas mismas cualidades morales que hacen que la vida sea digna de prolongarse».

Este fantasma de dominio está, sin embargo, en el ambiente el desmembramiento sistemático del cuerpo y la explotación de todas sus sustancias, ya no tiene desde ahora que infligirse la paciencia de esperar la muerte del individuo para apoderarse del cadáver, se puede hoy en día "segar» al vivo. Un filósofo americano, William May, se pregunta si la capacidad de ofenderse u horrorizarse no es un componente propiamente humano y esencial para la vida social. De estas o aquellas prácticas e ilusiones penden estos sentimientos, quitan importancia a las rupturas antropológicas que no son sin consecuencias. Diluyendo la definición del hombre, emborronando la muerte, proponiéndose hacer útiles a los muertos, no perder nada del cadáver, ¿la medicina que se compromete en esta vía no iguala los valores y de este hecho no los suprime? ¿No hace la medicina que la vida sea incómoda suspendiendo los datos antropológicos que condicionan hasta ahora el funcionamiento de las sociedades humanas; una definición precisa y unánime de la muerte, una definición de la persona, etc.? May percibe «un matiz de inhumanidad en lo humanitario de estos que creen que la percepción de lo social debe fácilmente prevalecer sobre cualquier otra consideración y reducir los actos de instrumentalización a la

15 W. GaYlin, «Harvesting the dead», Harper's Magazine, núm. 249, septiembre 1974.

16 Gaylin cita a los niños como «débiles mentales» infectados deliberadamente con el virus de la hepatitis para probar sobre ellos los medicamentos. 
pura rutina de lo cotidiano» ${ }^{17}$. ¿Acaso las resistencias sociales a estos procesos médicos no son el fruto de una pura nostalgia sin porvenir o bien el último sobresalto de conciencia antes de un aligeramiento acentuado de los valores haciendo la vida difícil de orientar? ¿Son el hecho de una retaguardia moral destinada a desaparecer con un tiempo cada vez más hospitalario a estas iniciativas, o bien síntomas de una crisis moral de efectos sociales destructivos cuya amenaza presienten? La voluntad de poder sobre el cuerpo, sobre la muerte, ¿introduce un aumento de felicidad o miedo?

Esta visión biomédica que aísla al cuerpo y suspende al hombre como una hipótesis secundaria y sin duda despreciable, se confronta hoy en día a una resistencia social y a un cuestionamiento ético generalizado. Si el hombre no existe más que a través de las formas corporales que le traen al mundo, toda modificación de su forma implica otra definición de su humanidad. Si las fronteras del hombre están trazadas por la carne que lo compone, sustraer o añadirle otros componentes supone el riesgo de alterar su identidad personal y perturbar las marcas que lo conciernen a los ojos de los demás. En una palabra, si el cuerpo es un símbolo de la sociedad, según lo sugiere Mary Douglas, toda amenaza de su forma afecta simbólicamente al lazo social ${ }^{18}$. Los límites del cuerpo dibujan a su escala el orden moral y significativo del mundo. Pensar el cuerpo es otra forma de pensar el mundo y el vínculo social; un trastorno introducido en la configuración del cuerpo es un desorden introducido en la coherencia del mundo ${ }^{19}$.

(Traducción: Marta MELERO GÓMEZ.

Revisado por Daniel BORRILlO.)

17 William MAY, "Attitudes toward the newly dead», The Hastings Center Studies, vol. 1, 1993, p. 5.

18 Mary Douglas, Purity and danger. An Analysis of the concepts of pollution and taboo, Londres, Routledge and Kegan Paul, 1984.

19 David Le Breton, La chair à vif, op. cit. 


\title{
RESUMEN
}

De ahora en adelante, la unidad fenomenológica del hombre estará fragmentada en la representación científica contemporánea y en las realizaciones de la biomedicina. Para la tecnociencia, la especie humana parece teñirse de una corporeidad acorde a la humildad de su condición. El cuerpo no es un lugar de dominio para la clase médica o la ingeniería, cuyo fin último sería llevarlo a la perfección buscando la corrección de la ciencia.

\begin{abstract}
From now on, the phenomenological unity of the human being will be fragmented into the contemporaneous scientific representation and into biomedicine realizations. For the techoscience, humans seem to be tinged with a corporeal nature in harmony with the lowliness of its condition. The body is not a place of dominion for the medical class or enginiering, which could have at a last end the perfection looking for science complexion.
\end{abstract}

